\title{
Responsabilidade Social em Relação ao Público Interno: Um Estudo Comparativo entre as Empresas do ISE e do IBrX
}

\author{
Letícia Tessmann \\ Mestrado em andamento em Ciências Contábeis pela Universidade do Vale do Rio dos \\ Sinos - UNISINOS \\ Av. Unisinos, 950. São Leopoldo/RS. CEP: 93022-010 \\ E-mail: leticia.tessmann@gmail.com
}

Angela Patrícia Bovolini Pedron Mestrado em andamento em Ciências Contábeis pela Universidade do Vale do Rio dos Sinos - UNISINOS

Av. Unisinos, 950. São Leopoldo/RS. CEP: 93022-010

E-mail: angelpedron@hotmail.com

Mariana Manfroi da Silva Mestrado em andamento em Ciências Contábeis pela Universidade do Vale do Rio dos

Sinos - UNISINOS

Av. Unisinos, 950. São Leopoldo/RS. CEP: 93022-010

E-mail: mariana@zjscontabilidade.com.br

Rubens dos Santos

Mestrado em andamento em Ciências Contábeis pela Universidade do Vale do Rio dos

Sinos - UNISINOS

Av. Unisinos, 950. São Leopoldo/RS. CEP: 93022-010

E-mail: rubens.contabeis.unemat@gmail.com

\section{RESUMO}

O mundo globalizado e as novas relações de negócios têm modificado o papel da empresa na sociedade; ela deve buscar não só a geração de riqueza para si, mas deve também preocupar-se em investir na preservação do meio ambiente, melhorando as condições da comunidade na qual ela está inserida e investir em seus funcionários. Diante disso, analisou-se os Balanços Sociais do ano de 2009 das empresas integrantes do ISE e das empresas que compõem o IBrX com o objetivo de identificar o percentual investido em relação ao público interno, ou seja, com seus funcionários e colaboradores. Apresentam-se noções de ética empresarial, transformada em responsabilidade social pelas empresas frente aos seus diferentes públicos envolvidos. O estudo empírico de natureza aplicada se enquadra como pesquisa descritiva e documental. Foram comparados os valores despendidos em folha de pagamento, por ser 0 investimento de maior valor agregado aos funcionários, e os benefícios concedidos como: auxílio-creche, plano de saúde, vale refeição, entre outros. Conclui- 
se que as empresas do ISE investem mais do que as empresas do $\mathrm{IBrX}$ em seus colaboradores, entretanto os investimentos ainda são baixos e a divulgação do balanço social ainda é pouco utilizada pelas empresas.

Palavras-Chave: Responsabilidade Social Empresarial. Balanço Social. Ética Empresarial.

\title{
Social Responsibility with Internal Public: A Comparative Study between ISE and IBrX Companies
}

\begin{abstract}
The globalized world and new business relationships have changed the role of business in society. They should seek not only to create wealth for themselves, but also worry about investing in environment protection, improving the conditions of the community in which it is inserted and invest in their employees. We analyzed the Social Balance of 2009 of the ISE and IBrX firms in order to identify the percentage invested in internal public. Notions of business ethics, transformed into corporate social responsibility to attend different audiences, are presented. The empirical study of an applied nature qualifies as descriptive and documentary. We compared the amounts spent on payroll, as the investment of greater value to employees, and benefits such as day-care assistance, health insurance, meal vouchers, and other. We conclude that the ISE companies invest more than the $\mathrm{IBr}$ in its employees, however the investments are still low and the dissemination of the social is still little used by businesses.
\end{abstract}

Keywords: Social Responsibility. Social Balance. Business Ethics.

\section{INTRODUÇÃO}

A divulgação de informações sociais pelas empresas tem se tornado cada vez mais um diferencial competitivo. A empresa que investe em seus funcionários e visa além do pagamento daquilo que é legal; a instituição que cria projetos sociais de inclusão e melhoria da comunidade na qual ela está inserida; e aquela que investe no meio ambiente, buscando fontes alternativas de energia, matéria-prima de primeira linha e investe em pesquisas para diminuição de gases tóxicos, apresenta um diferencial que é bem visto pela sociedade e levado em conta pelos investidores.

A responsabilidade social empresarial é tão importante que na BM\&FBovespa há uma classificação para as empresas que investem em ações sociais. Trata-se do Índice de Sustentabilidade Empresarial (ISE), do qual fazem parte as empresas 
consideradas socialmente responsáveis, de tal forma que os acionistas que investem nestas empresas têm a certeza de que elas investem na sociedade, no meio ambiente e nos seus funcionários.

Dada a repercussão e complexidade do tema responsabilidade social, para cuja análise são necessárias considerações de múltiplos elementos e inter-relações, o mesmo tem despertado um grande interesse por parte de diversos segmentos da sociedade, bem como do meio acadêmico. Nessa linha se insere o artigo proposto, esperando-se que contribua para ampliar o conhecimento acerca do tema, e que a divulgação dos seus resultados sirva para que gestores que ainda não atentaram para esta nova realidade possam considerá-la como um elemento importante no planejamento das atividades em suas empresas.

Assim, o objetivo do presente estudo é identificar o volume de recursos despendidos com o público interno, ou seja, com seus funcionários e colaboradores, aqueles que acabam diretamente gerando a riqueza da empresa com o seu trabalho, partindo da premissa que as empresas que estão classificadas no ISE se diferenciam socialmente de outras empresas, trazendo maiores benefícios e investimentos à sociedade. Já as do $\mathrm{IBrX}$ são as empresas que possuem o maior número de negociações na bolsa, entretanto não necessariamente investem montantes expressivos em ações sociais.

A justificativa da análise está em verificar se o retorno financeiro ao funcionário é maior em empresas classificadas no ISE, calculando o percentual investido no público interno das empresas em relação ao seu resultado operacional, uma vez que as empresas componentes deste índice são consideradas referências de comportamento socialmente responsável entre as empresas de capital aberto.

Além dessa introdução, o artigo apresenta na fundamentação teórica tópicos sobre ética empresarial, responsabilidade social empresarial e balanço social, seguidos dos procedimentos metodológicos utilizados, das análises dos resultados obtidos, da conclusão e das referências. 


\section{FUNDAMENTAÇÃO TEÓRICA}

\section{1 Ética Empresarial}

A ética é a essência de um comportamento e postura correta diante do próximo. Uma empresa ética é aquela que respeita a sociedade, o meio ambiente, seus funcionários e vende produtos de qualidade para seus consumidores.

A ética como ética teórica não modifica o comportamento e a sociedade, entretanto, uma ética aplicada que busca uma validez em uma instituição, e é vivenciada pelos seus funcionários, fornecedores, clientes e sociedade, modifica as relações do mercado e torna esta empresa co-responsável de uma transformação social. "Em ética aplicada, não se trata apenas de empregar princípios definidos através do processo de fundamentação, mas de aplicá-los a casos específicos" (PIZZI, 2006, p.17).

Garcia-Marzá (2004, p.115) entende que "enquanto a teoria ética se encarrega de fundamentar e explicitar o ponto de vista moral, a ética aplicada pressupõe a validez do princípio moral e se ocupa da questão de sua realização".

A ética aplicada, portanto, tem como objetivo a realização dos princípios morais dentro de contextos e situações concretas de forma a orientar o desenvolvimento de espaços de liberdade, e, portanto, tornar mais responsáveis e racionais esses distintos contextos, práticas e instituições.

A ética nas empresas como ética aplicada, parte da realidade da empresa como uma instituição econômico-social, que vai além da busca do lucro e da geração de riquezas, ela se propõe a inovar e a criar propostas éticas e rentáveis. Trata-se de uma busca crescente entre as empresas que pretendem se destacar não só pela geração de lucros, mas vão além do lucro tornando-o a consequência da sua atividade, através de um comportamento responsável diante de seus stakeholders. "No caso da ética empresarial, o objetivo consiste em aprofundar a qualidade ética na tomada de decisões. [...] Na verdade trata-se de responder positivamente frente às expectativas morais depositadas na empresa" (GARCIA-MARZÁ, 2004, p.118).

O autor menciona, ainda, que "a ética empresarial, como ética aplicada, é parte de uma ética cívica, que se compreende como uma determinada modelagem ou 
realização dos valores e normas, compartilhados por uma sociedade pluralista, dentro da empresa como instituição" (GARCIA-MARZÁ, 2004, p.125).

Esta busca por parte das empresas por uma ética empresarial confirma uma nova forma de gestão que não visa somente o lucro como única prioridade, mas em agir de forma a gerar a confiança e a satisfação de todos seus stakeholders. GarciaMarzá (2004, p.128) advoga por uma "ética dialógica, buscando ouvir todos os envolvidos na organização na busca de uma construção de um espaço ético na empresa".

Como se o observa, a ética empresarial está intimamente ligada a Responsabilidade Social, por se tratar de uma forma de conduzir os negócios da empresa de tal maneira que a torna parceira e co-responsável pelo desenvolvimento social.

\subsection{Responsabilidade Social Empresarial}

A Responsabilidade Social Empresarial é um compromisso ético assumido pela empresa diante dos seus stakeholders, promovendo a melhoria da qualidade de vida de seus colaboradores e suas famílias, da comunidade local, meio ambiente e da sociedade como um todo.

Segundo Ashley (2002, p.7),

a responsabilidade social pode ser definida como o compromisso que uma organização deve ter para com a sociedade, expresso por meio de atos e atitudes que a afetem positivamente, de modo amplo, ou alguma comunidade, de modo específico, agindo pro ativamente e coerentemente no que tange a seu papel específico na sociedade e a sua prestação de contas para com ela.

A empresa deve ser uma boa cidadã corporativa (como parte da sua responsabilidade social), não só porque isto incrementa seus benefícios, mas também porque ela tem uma obrigação moral de contribuir com o bem-estar da sociedade (ENDERLE, 2007). Ela pode ser vista como uma atitude que venha a contribuir com o bem-estar social sob seu aspecto mais amplo, envolvendo a sustentabilidade social e econômica e a minimização da desigualdade social. 
A responsabilidade social empresarial pode ser dividida em três grandes grupos: o público interno, que envolve funcionários e suas famílias, prestadores de serviços, ou seja, todos que colaboram com a empresa internamente; o público externo, que envolve a comunidade na qual ela está inserida e o meio ambiente.

\subsubsection{Público interno}

Um dos indicadores da responsabilidade social foca o público interno da empresa, ou seja, está voltado para seus funcionários, procurando capacitação e o bem-estar de seus colaboradores.

Para Lourenço e Schröder (2003), os gestores não deveriam assumir apenas o mínimo de responsabilidade em relação aos seus empregados mediante o respeito às obrigações empregado-empregador. Deveriam ultrapassar o simples atendimento às leis trabalhistas, buscando um alinhamento entre os objetivos estratégicos da organização e os interesses dos seus empregados. Isso significa investir no desenvolvimento pessoal dos empregados, melhorando as condições de trabalho, o relacionamento interno e incentivando o envolvimento dos empregados nas atividades da empresa, sempre respeitando elementos como cultura, crenças, religião e valores de cada indivíduo.

Uma empresa responsável é aquela que busca saber se seus funcionários estão satisfeitos com as condições físicas e ambientais como: a climatização do meio ambiente; iluminação; espaço físico; limpeza e manutenção; equipamentos; material de expediente e segurança. Outros pontos importantes dizem respeito ao relacionamento entre os colegas de mesmo setor; de outros setores e a chefia; a satisfação funcional em relação à remuneração; em relação ao mercado; à participação na tomada de decisões; trabalho ou atividade executada; à interação do trabalho com os demais setores e à imagem institucional.

Ser uma empresa socialmente responsável não significa somente dar vida a um projeto educativo ou realizar algumas ações de melhoria na prática dos negócios. É preciso desenvolver internamente pessoas que sejam socialmente responsáveis. Somente contando com pessoas capazes de pensar e agir dessa forma pode-se desenvolver internamente a cultura da responsabilidade social e fazer com que esta 
transcenda os limites da empresa (BULLARA, 2003).

A busca da melhoria na qualidade de vida dos funcionários se reflete positivamente na diminuição dos gastos com saúde e assistência social, pois estes se tornam mais imunes às doenças profissionais, em especial, o estresse. Tende a aumentar a auto-estima, proporcionando uma melhoria no clima organizacional da empresa. O exercício da responsabilidade social com o público interno resulta de forma positiva na qualidade dos produtos e serviços oferecidos, aumentando 0 comprometimento e a motivação do funcionário com a empresa.

\subsubsection{Público externo}

A relação da responsabilidade social da empresa com o público externo está nos investimentos e projetos realizados em relação à comunidade na qual ela está inserida. Nesse sentido, Meira e Oliveira (2006) ressaltam que a responsabilidade social externa tem como foco a comunidade mais próxima da empresa ou o local onde ela está situada.

Segundo a Comissão das Comunidades Europeias (2001, p.12),

a responsabilidade social de uma empresa ultrapassa a esfera da própria empresa e estende-se à comunidade local, envolvendo, para além dos trabalhadores e acionistas, um vasto espectro de outras partes interessadas: parceiros comerciais e fornecedores, clientes, autoridades públicas e ONG que exercem a sua atividade junto das comunidades locais ou no domínio do ambiente.

A responsabilidade social voltada ao público externo não se limita somente a venda de bons produtos, ela está ligada a projetos voltados à sociedade. A empresa socialmente responsável é aquela que busca criar um espaço dialógico com a comunidade na qual ela está inserida, buscando ouvir as diferentes partes e assim desenvolver projetos que resolvam as reais necessidades da comunidade.

Ainda, para a Comissão das Comunidades Européias (2001, p.12), 
a empresa que assume o compromisso com a melhoria da qualidade de vida da sociedade, com venda de bons produtos, com a compra de matéria-prima de primeira linha e ecologicamente correta, com a busca de ações sociais voltadas para o bem-estar da comunidade; verifica que estas ações acarretam retorno para a empresa sob todos os aspectos: econômico, financeiro e social. As empresas acabam também contribuindo para a vida da comunidade local em termos de emprego, remuneração, benefícios e impostos.

Além de todas estas consequências positivas que são geradas pela adoção de ações sociais, no momento em que a empresa assume uma postura ética, acaba adquirindo maior credibilidade e confiança diante de seu público externo. Estes estão cada vez mais exigindo uma postura ética e responsável das empresas, o que significa que escolherão empresas que estabelecem boa relação com seus funcionários, preservam o meio ambiente e investem na sua comunidade. Essa mudança na postura da entidade pode gerar aumento de faturamento e melhoria da sua imagem e dos seus resultados.

\subsection{Meio ambiente}

A responsabilidade social perante o meio ambiente talvez seja uma das mais importantes e evidentes nos últimos tempos, devido à escassez dos recursos naturais, das catástrofes ambientais que têm acontecido pelo consumo desenfreado e pela produção sem preocupação com a preservação e políticas de proteção ao meio ambiente.

Segundo Lisboa e Ribeiro (1999, p.4 - 5), 
durante séculos as atividades econômicas foram instaladas e mantidas sem qualquer preocupação ambiental. Através disso, encontram-se hoje em dia grandes extensões de águas correntes e solos totalmente poluídos e improdutivos. $O$ ar com grande quantidade de emissões tóxicas causa dos diversos casos de doenças respiratórias e dermatológicas. Diante desta situação alarmante, as novas tecnologias produzidas estão impulsionadas a conter estes efeitos danosos. Muitas empresas deixam de investir em uma gestão ambiental devido aos elevados custos que estas novas tecnologias acarretam. Esta resistência empresarial começou a ser combatida pelas pressões de movimentos ambientalistas, que exigiram ações governamentais de cobrança por fiscalizações mais rigorosas na exigência da gestão ambiental, e que por fim culminaram com o surgimento da consciência de responsabilidade social das empresas e a criação das normas internacionais de qualidade ambiental.

Possivelmente as empresas consideradas poluidoras, que não adotarem medidas preventivas para solucionar problemas ambientais, poderão encontrar dificuldades na aceitação dos seus produtos e na autorização para o seu funcionamento, devido ao risco que oferecem para a sociedade.

Segundo Enderle (2007), a empresa deve estar comprometida com o "desenvolvimento sustentável". A empresa tem de se comprometer a consumir menos recursos naturais e a aliviar o meio ambiente de águas residuais. Cada vez mais estas empresas sofrerão 'pressão' da sociedade para adotarem modos de produção não poluentes, utilizem matéria-prima de qualidade e que tenham pesquisas voltadas à despoluição de rios já poluídos por elas, assumindo assim uma postura ética diante da sociedade, pois elas demonstram que se preocupam com a preservação dos recursos naturais, disponibilizando-os às gerações futuras.

\subsection{Balanço Social}

O balanço social é um instrumento que vai além de uma demonstração contábil da empresa, ele mostra todos os projetos de responsabilidade social que a empresa mantém e demonstra por meio da Demonstração do Valor Adicionado o quanto ela gerou de riqueza bem como essa riqueza foi distribuída aos diversos grupos de 
interesse. Trata-se de um importante instrumento de demonstração da responsabilidade social das organizações, que permite a avaliação do seu desempenho na área social em determinado período. Nesse instrumento, são discriminadas as ações sociais quanto a sua natureza, seja de responsabilidade social interna, externa ou ambiental (MEIRA; OLIVEIRA, 2006).

Batista (2000) menciona que em relação aos dados que compõem o Balanço Social, sejam quantitativos ou qualitativos, e independente do montante dos investimentos tangíveis ou intangíveis, a confirmação dos elementos sempre se dá via contabilidade. Se assim não ocorrer, esta demonstração pode se resumir a uma peça ilustrativa de questionável veracidade ou mesmo de marketing.

Ética Empresarial, Responsabilidade Social e Balanço Social, não podem ser vistos como meros instrumentos de marketing pela empresa, nem como filantropia. Eles devem ser projetos contínuos e planejados com a comunidade local, na medida em que ela consegue identificar as áreas que necessitam de maior investimento, fazendo com que a empresa realmente contribua com a melhoria da comunidade e da sociedade de modo geral.

\section{PROCEDIMENTOS METODOLÓGICOS}

A pesquisa pode ser entendida como aplicada e descritiva, já que se descreve a realidade expressa nos documentos examinados, e que dependeram de interpretação dos pesquisadores. Segundo Gil (1999, p.44), "a pesquisa descritiva tem como objetivo primordial a descrição das características de determinada população ou fenômeno ou o estabelecimento de relações entre variáveis. Salientam-se aquelas que têm por objetivo estudar as características de um grupo".

Quanto aos procedimentos técnicos a pesquisa pode ser enquadrada como documental. Foram manuseados os Balanços Sociais das empresas classificadas no ISE e no IBrX visando encontrar os elementos relacionados a investimentos no público interno. O elemento identificado como o de maior representatividade em relação ao investimento no público interno é a folha de pagamento. Foi determinado o percentual da folha de pagamento em relação ao resultado operacional, por se tratar do resultado 
alcançado somente com as atividades operacionais da empresa.

De acordo com Silva (2006, p.55), "pesquisa documental trata de uma investigação documental feita em documentos conservados em órgãos públicos e privados [...] nesta os documentos precisam passar por uma análise interna e externa, evitando preferências pessoais".

Deu-se ênfase aos investimentos no público interno, já que estes são os maiores colaboradores para a geração direta da riqueza da empresa e estas informações no balanço social se referem às informações relacionadas com as ações sociais destinadas para os funcionários ou colaboradores.

Foram utilizados os balanços sociais publicados em 2009 pelas empresas do ISE e do IBrX, visando traçar um comparativo entre os investimentos efetuadas em favor de seus públicos internos. Os quadros e tabelas utilizadas foram baseados em estudo realizado por Milani Filho (2008).

As empresas classificadas no ISE e cujos dados foram utilizados para análise nesta pesquisa constam no Quadro 1. 
Responsabilidade Social em Relação ao Público Interno: Um Estudo Comparativo entre as

Empresas do ISE e do IBrX

Letícia Tessmann, Angela Patrícia Bovolini Pedron, Mariana Manfroi da Silva, Rubens dos Santos

\begin{tabular}{|c|c|}
\hline Setor & Razão Social \\
\hline Bens Indls / Máqs e Equips & INDUSTRIAS ROMI S.A \\
\hline Bens Indls / Mat Transporte & EMBRAER S.A \\
\hline Cons N Básico / Alimentos Processados & BRF - BRASIL FOODS S.A. \\
\hline Cons N Cíclico / Pr Pessoal Limp & NATURA COSMETICOS S.A. \\
\hline Const e Transp / Constr e Engenh & EVEN CONSTRUTORA E INCORPORADORA S.A. \\
\hline Consumo não Cíclico/Saúde & DIAGNOSTICOS DA AMERICA S.A. \\
\hline Financ e Outros / Interms Financs & BCO BRADESCO S.A. \\
\hline Financ e Outros / Previd Seguros & BCO BRASIL S.A. \\
\hline Financeiro e Outros/Serviços Financeiros & ITAUSA INVESTIMENTOS ITAU S.A. \\
\hline Diversos & ITAU UNIBANCO HOLDING S.A. \\
\hline Mats Básicos / Madeira e Papel & SUL AMERICA S.A. \\
\hline Financeiro e Outros/Serviços Financeiros & REDECARD S.A. \\
\hline Diversos & \\
\hline \multirow{3}{*}{ Mats Básicos / Madeira e Papel } & DURATEXS.A. \\
\hline & FIBRIA CELULOSE S.A. \\
\hline & SUZANO PAPEL E CELULOSE S.A. \\
\hline Mats Básicos / Químicos & BRASKEM S.A. \\
\hline \multirow{3}{*}{ Mats Básicos / Sid Metalurgia } & GERDAU S.A. \\
\hline & METALURGICA GERDAU S.A. \\
\hline & USINAS SID DE MINAS GERAIS S.A.- USIMINAS \\
\hline Telecomunicação / Telefonia Fixa & TELE NORTE LESTE PARTICIPACÕES S.A. \\
\hline \multirow{2}{*}{ Telecomunicação / Telefonia Móvel } & TIM PARTICIPACOES S.A. \\
\hline & VIVO PARTICIPACOES S.A. \\
\hline Utilidade Públ / Água Saneamento & CIA SANEAMENTO BASICO EST SÃO PAULO \\
\hline \multirow[t]{11}{*}{ Utilidade Públ / Energ Elétrica } & AES TIETE S.A. \\
\hline & CIA ENERGETICA DE MINAS GERAIS - CEMIG \\
\hline & CESP - CIA ENERGETICA DE SÃO PAULO \\
\hline & CIA ENERGETICA DO CEARA - COELCE \\
\hline & CIA PARANAENSE DE ENERGIA - COPEL \\
\hline & CPFL ENERGIA S.A. \\
\hline & CENTRAIS ELET BRAS S.A. - ELETROBRAS \\
\hline & ELETROPAULO METROP. ELET. SAO PAULO S.A. \\
\hline & EDP - ENERGIAS DO BRASIL S.A. \\
\hline & LIGHT S.A. \\
\hline & TRACTEBEL ENERGIA S.A. \\
\hline
\end{tabular}

Quadro 1 - Setores e Empresas do ISE 
Responsabilidade Social em Relação ao Público Interno: Um Estudo Comparativo entre as

Empresas do ISE e do IBrX

Letícia Tessmann, Angela Patrícia Bovolini Pedron, Mariana Manfroi da Silva, Rubens dos Santos

Dentre as 100 empresas com ações constantes no IBrX foram selecionadas, por percentual de participação na carteira, as 34 empresas com maior representatividade, excluindo as empresas que fazem parte do ISE, conforme Quadro 2. 
Responsabilidade Social em Relação ao Público Interno: Um Estudo Comparativo entre as

Empresas do ISE e do IBrX

Letícia Tessmann, Angela Patrícia Bovolini Pedron, Mariana Manfroi da Silva, Rubens dos Santos

\begin{tabular}{|c|c|}
\hline Setor & Razão Social \\
\hline \multirow[t]{3}{*}{ Bens Indls / Máqs e Equips } & WEG S.A \\
\hline & COSAN S.A. INDÚSTRIA E COMÉRCIO \\
\hline & JBS S.A \\
\hline $\begin{array}{l}\text { Cons N Básico / Alimentos } \\
\text { Processados }\end{array}$ & MARFRIG ALIMENTOS S/A \\
\hline Cons N Cíclico / Bebidas & CIA BEBIDAS DAS AMERICAS - AMBEV \\
\hline Cons N Cíclico / Comércio Distr. & CIA BRASILEIRA DE DISTRIBUIÇÃO \\
\hline Cons N Cíclico / Fumo & SOUZA CRUZ S.A \\
\hline \multirow[t]{4}{*}{ Cons N Cíclico/Diversos } & HYPERMARCAS S.A. \\
\hline & $\begin{array}{l}\text { CYRELA BRAZIL REALTY S.A.EMPREEND E } \\
\text { PART }\end{array}$ \\
\hline & GAFISA S.A. \\
\hline & MRV ENGENHARIA E PARTICIPACOES S.A. \\
\hline \multirow[t]{3}{*}{ Const e Transp / Constr e Engenh } & $\begin{array}{c}\text { PDG REALTY S.A. EMPREEND E } \\
\text { PARTICIPACOES }\end{array}$ \\
\hline & ALL AMERICA LATINA LOGISTICA S.A. \\
\hline & CIA CONCESSOES RODOVIARIAS \\
\hline Const e Transp / Transporte & TAM S.A. \\
\hline \multirow{2}{*}{ Consumo Cíclico / Comércio } & LOJAS AMERICANAS S.A. \\
\hline & LOJAS RENNER S.A. \\
\hline \multirow[t]{2}{*}{ Diversos } & LOCALIZA RENT A CAR S.A. \\
\hline & MULTIPLAN - EMPREEND IMOBILIARIOS S.A. \\
\hline \multirow[t]{2}{*}{ Financ e Outros / Explor Imóveis } & BR MALLS PARTICIPACOES S.A. \\
\hline & BRADESPAR S.A. \\
\hline Financ e Outros / Holdings Divers & ULTRAPAR PARTICIPACOES S.A. \\
\hline Financ e Outros / Interms Financs & BCO ESTADO DO RIO GRANDE DO SUL S.A. \\
\hline \multirow[t]{3}{*}{ Financ e Outros / Previd Seguros } & PORTO SEGURO S.A. \\
\hline & $\begin{array}{c}\text { BMFBOVESPA S.A. BOLSA VALORES MERC } \\
\text { FUT }\end{array}$ \\
\hline & $\begin{array}{l}\text { CETIP S.A. - BALCÃO ORGANIZADO DE } \\
\text { ATIVOS E DERIV. }\end{array}$ \\
\hline $\begin{array}{l}\text { Financeiro e Outros/Serviços } \\
\text { Financeiros Diversos }\end{array}$ & CIELO S.A. \\
\hline \multirow[t]{2}{*}{ Mats Básicos / Madeira e Papel } & KLABIN S/A \\
\hline & MMX MINERACAO E METALICOS S.A. \\
\hline Mats Básicos / Mineração & VALE S.A. \\
\hline \multirow[t]{2}{*}{ Mats Básicos / Sid Metalurgia } & CIA SIDERURGICA NACIONAL \\
\hline & $\begin{array}{c}\text { OGX PETROLEO E GAS PARTICIPACOES } \\
\text { S.A. }\end{array}$ \\
\hline Petróleo, Gás e Biocombustíveis & PETROLEO BRASILEIRO S.A. PETROBRAS \\
\hline Telecomunicação / Telefonia Fixa & BRASIL TELECOM S.A. \\
\hline
\end{tabular}

Quadro 2 - Setores e Empresas do IBrX 


\section{ANÁLISE COMPARATIVA ENTRE OS BALANÇOS SOCIAIS DAS EMPRESAS DO ISE E DO IBrX}

\section{a) Divulgação do Balanço Social}

A divulgação de dados no Balanço Social tornou-se uma prática pelas empresas que tem como princípio intrínseco as suas atividades e o desenvolvimento social. As empresas pertencentes ao ISE e $\mathrm{IBrX}$ que divulgam Balanço Social estão apresentadas na Tabela 1. 
Responsabilidade Social em Relação ao Público Interno: Um Estudo Comparativo entre as

Empresas do ISE e do IBrX

Letícia Tessmann, Angela Patrícia Bovolini Pedron, Mariana Manfroi da Silva, Rubens dos Santos

Tabela 1 - Divulgação do Balanço Social por Setor

\begin{tabular}{|c|c|c|c|c|c|}
\hline Setor & $\begin{array}{l}\text { Qtd. de } \\
\text { empresas }\end{array}$ & $\begin{array}{c}\text { Publicam } \\
\text { BS }\end{array}$ & Part. & ISE & $\begin{array}{l}\text { Das que } \\
\text { publicam } \\
\text { IBRX }\end{array}$ \\
\hline Máquinas e Equipamentos & 2 & 1 & $50 \%$ & 0 & 1 \\
\hline Aeroespacial & 1 & 1 & $100 \%$ & 1 & 0 \\
\hline Alimentos Processados & 4 & 1 & $25 \%$ & 1 & 0 \\
\hline Bebidas & 1 & 0 & $0 \%$ & 0 & 0 \\
\hline Comércio e Distribuição & 1 & 1 & $100 \%$ & 0 & 1 \\
\hline Fumo & 1 & 0 & $0 \%$ & 0 & 0 \\
\hline Diversos & 1 & 0 & $0 \%$ & 0 & 0 \\
\hline Produtos de Uso Pessoal & 1 & 0 & $0 \%$ & 0 & 0 \\
\hline Construção e Engenharia & 5 & 0 & $0 \%$ & 0 & 0 \\
\hline Transporte & 3 & 3 & $100 \%$ & 0 & 3 \\
\hline Comércio & 2 & 0 & $0 \%$ & 0 & 0 \\
\hline Serviços de Locação & 1 & 1 & $100 \%$ & 0 & 1 \\
\hline Saúde & 1 & 0 & $0 \%$ & 0 & 0 \\
\hline Intermediação Financeira & 5 & 1 & $20 \%$ & 0 & 1 \\
\hline Exploração de Imóveis & 2 & 0 & $0 \%$ & 0 & 0 \\
\hline Holdings & 2 & 0 & $0 \%$ & 0 & 0 \\
\hline Previdência e Seguros & 2 & 1 & $50 \%$ & 0 & 1 \\
\hline Serviços Financeiros & 4 & 1 & $25 \%$ & 1 & 0 \\
\hline Madeira e Papel & 4 & 3 & $75 \%$ & 2 & 1 \\
\hline Mineração & 2 & 0 & $0 \%$ & 0 & 0 \\
\hline Químicos & 1 & 0 & $0 \%$ & 0 & 0 \\
\hline Siderurgia e Metalurgia & 4 & 2 & $50 \%$ & 2 & 0 \\
\hline $\begin{array}{l}\text { Petróleo, Gás e } \\
\text { Biocombustíveis }\end{array}$ & 2 & 1 & $50 \%$ & 0 & 1 \\
\hline Telefonia Fixa & 2 & 0 & $0 \%$ & 0 & 0 \\
\hline Telefonia Móvel & 2 & 1 & $50 \%$ & 1 & 0 \\
\hline Água Saneamento & 1 & 1 & $100 \%$ & 1 & 0 \\
\hline Energia Elétrica & 11 & 8 & $73 \%$ & 8 & 0 \\
\hline Total & 68 & 27 & $40 \%$ & 17 & 10 \\
\hline $\begin{array}{c}\text { Percentual em relação as } \\
\text { que publicam }\end{array}$ & & & & $63 \%$ & $37 \%$ \\
\hline
\end{tabular}

Pelos dados apresentados é possível verificar maior divulgação do Balanço Social pelas empresas componentes do ISE, destacando-se o setor de energia elétrica. Dentre as empresas do IBrX verifica-se menor divulgação, principalmente nos setores que utilizam recursos naturais ou que podem provocar impactos à sociedade como 0 
setor de bebidas, fumo, químico, mineração e siderurgia e metalurgia.

\section{b) Investimento no Público Interno}

A divulgação do Balanço Social torna possível verificar-se, por meio de métrica comparativa, o montante despendido em termos de folha de pagamento (FP) em relação ao resultado operacional $(\mathrm{RO})$ nas empresas componentes do ISE e as do $\mathrm{IBrX}$. Considerando a folha de pagamento um indicador ligado diretamente ao resultado operacional e sendo este um investimento de maior valor da empresa em relação aos seus colaboradores, esta comparação se faz necessária para verificar se as empresas tidas como socialmente responsáveis (ISE) investem mais em seus funcionários do que as empresas do IBrX. 
Responsabilidade Social em Relação ao Público Interno: Um Estudo Comparativo entre as

Empresas do ISE e do IBrX

Letícia Tessmann, Angela Patrícia Bovolini Pedron, Mariana Manfroi da Silva, Rubens dos Santos

Tabela 2 - Percentual da Folha de Pagamento em Relação ao Resultado Operacional - ISE

\begin{tabular}{|c|c|c|}
\hline Setor & $\begin{array}{c}\text { Qtd. de } \\
\text { empresas }\end{array}$ & Part. FP/RO \\
\hline Alimentos Processados & 1 & $756 \%$ \\
\hline Serviços Financeiros & 1 & $5 \%$ \\
\hline Madeira e Papel & 2 & $45 \%$ \\
\hline Siderurgia e Metalurgia & 2 & $94 \%$ \\
\hline Telefonia Móvel & 1 & $236 \%$ \\
\hline Água Saneamento & 1 & $61 \%$ \\
\hline Energia Elétrica & 8 & $26 \%$ \\
\hline $\begin{array}{l}\text { Total (empresas ISE que } \\
\text { publicam Balanço Social) }\end{array}$ & 17 & \\
\hline Média setores & & $175 \%$ \\
\hline Desvio padrão & & 2,48 \\
\hline Média 17 empresas & & $101 \%$ \\
\hline Desvio padrão 17 empresas & & 1,81 \\
\hline Máquinas e Equipamentos & 1 & $0 \%$ \\
\hline Produtos de Uso Pessoal & 1 & $0 \%$ \\
\hline Construção e Engenharia & 1 & $0 \%$ \\
\hline Saúde & 1 & $0 \%$ \\
\hline Intermediação Financeira & 4 & $0 \%$ \\
\hline Previdência e Seguros & 1 & $0 \%$ \\
\hline Madeira e Papel & 1 & $0 \%$ \\
\hline Químicos & 1 & $0 \%$ \\
\hline Siderurgia e Metalurgia & 1 & $0 \%$ \\
\hline Telefonia Fixa & 1 & $0 \%$ \\
\hline Telefonia Móvel & 1 & $0 \%$ \\
\hline Energia Elétrica & 3 & $0 \%$ \\
\hline \multicolumn{3}{|l|}{$\begin{array}{l}\text { Total (empresas ISE que } \\
\text { não publicam Balanço }\end{array}$} \\
\hline Social) & 17 & \\
\hline Total ISE & 34 & \\
\hline Média todos os setores ISE & & $70 \%$ \\
\hline Desvio-padrão & & 1,74 \\
\hline Média (34 Empresas) & & $51 \%$ \\
\hline Desvio-padrão & & 1,37 \\
\hline
\end{tabular}


Responsabilidade Social em Relação ao Público Interno: Um Estudo Comparativo entre as

Letícia Tessmann, Angela Patrícia Bovolini Pedron, Mariana Manfroi da Silva, Rubens dos Santos

O setor que apresenta maior retorno aos seus funcionários, em relação à folha de pagamento, é o setor de alimentos processados, com um percentual de $756 \%$ do seu resultado operacional, em segundo lugar com $236 \%$ a telefonia móvel e em terceiro lugar com $174 \%$ a aeroespacial, os outros setores investem abaixo de $100 \%$ do seu resultado operacional.

A tabela a seguir apresenta informações sobre a relação entre folha de pagamento e resultado operacional das empresas constantes no $\mathrm{IBrX}$. 


\section{Responsabilidade Social em Relação ao Público Interno: Um Estudo Comparativo entre as \\ Empresas do ISE e do IBrX}

Letícia Tessmann, Angela Patrícia Bovolini Pedron, Mariana Manfroi da Silva, Rubens dos Santos

Tabela 3 - Percentual da Folha de Pagamento em Relação ao Resultado Operacional - IBrX

\begin{tabular}{|c|c|c|}
\hline Setor & Qtd. De empresas & Part. FP/RO \\
\hline $\begin{array}{c}\text { Máquinas e } \\
\text { Equipamentos }\end{array}$ & 1 & $121 \%$ \\
\hline Comércio e Distribuição & 3 & $211 \%$ \\
\hline Transporte & 1 & $225 \%$ \\
\hline Serviços de Locação & 1 & $103 \%$ \\
\hline Intermediação Financeira & 1 & $106 \%$ \\
\hline Previdência e Seguros & 1 & $170 \%$ \\
\hline Madeira e Papel & 1 & $50 \%$ \\
\hline $\begin{array}{l}\text { Petróleo, Gás e } \\
\text { Biocombustíveis }\end{array}$ & 1 & $24 \%$ \\
\hline $\begin{array}{l}\text { Total (empresas IBRX que } \\
\text { publicam Balanço Social) }\end{array}$ & 10 & \\
\hline Média setores & & $126 \%$ \\
\hline Desvio padrão & & 0,72 \\
\hline Média 10 empresas & & $146 \%$ \\
\hline $\begin{array}{c}\text { Desvio padrão } 10 \\
\text { empresas }\end{array}$ & & 1,68 \\
\hline Alimentos Processados & 3 & $0 \%$ \\
\hline Bebidas & 1 & $0 \%$ \\
\hline Fumo & 1 & $0 \%$ \\
\hline Diversos & 1 & $0 \%$ \\
\hline Construção e Engenharia & 4 & $0 \%$ \\
\hline Comércio & 2 & $0 \%$ \\
\hline Exploração de Imóveis & 2 & $0 \%$ \\
\hline Holdings & 2 & $0 \%$ \\
\hline Serviços Financeiros & 3 & $0 \%$ \\
\hline Mineração & 2 & $0 \%$ \\
\hline Siderurgia e Metalurgia & 1 & $0 \%$ \\
\hline $\begin{array}{l}\text { Petróleo, Gás e } \\
\text { Biocombustíveis }\end{array}$ & 1 & $0 \%$ \\
\hline Telefonia Fixa & 1 & $0 \%$ \\
\hline $\begin{array}{c}\text { Total (empresas IBRX que } \\
\text { não publicam Balanço } \\
\text { Social) } \\
\end{array}$ & 24 & \\
\hline Total IBRX & 34 & \\
\hline Média todos os setores & & $48 \%$ \\
\hline Desvio-padrão & & 0,76 \\
\hline Média (34 Empresas) & & $43 \%$ \\
\hline Desvio-padrão & & 1,11 \\
\hline
\end{tabular}


O setor que apresenta o maior percentual da folha de pagamento em relação ao resultado operacional é o setor de transporte com $225 \%$, seguido do setor de comércio e distribuição com $211 \%$ e do setor de previdência e seguros com $170 \%$.

Pelos dados obtidos pode-se verificar uma média percentual maior entre a folha de pagamento e o resultado operacional das empresas constantes no ISE; 70\% daquelas que apresentam o balanço social e $51 \%$ das que não divulgam o balanço social; em relação às constantes no $\mathrm{IBrX}$; $48 \%$ daquelas que apresentam o balanço social e $43 \%$ das que não o divulgam.

\section{c) Demais Benefícios Concedidos ao Público Interno}

Complementando as informações sociais com relação ao público interno, cabe uma análise comparativa entre os demais benefícios que as empresas concedem aos seus funcionários nas empresas constantes no ISE com as do IBrX. 


\section{Responsabilidade Social em Relação ao Público Interno: Um Estudo Comparativo entre as \\ Empresas do ISE e do IBrX}

Letícia Tessmann, Angela Patrícia Bovolini Pedron, Mariana Manfroi da Silva, Rubens dos Santos

Tabela 4 - Outros Investimentos Sociais Internos em Relação ao Resultado Operacional - ISE

\begin{tabular}{|c|c|c|}
\hline Setor & Qtd. De empresas & Part. FP/RO \\
\hline Aeroespacial & 1 & $77 \%$ \\
\hline Alimentos Processados & 1 & $252 \%$ \\
\hline Serviços Financeiros & 1 & $4 \%$ \\
\hline Madeira e Papel & 2 & $40 \%$ \\
\hline Siderurgia e Metalurgia & 2 & $55 \%$ \\
\hline Telefonia Móvel & 1 & $116 \%$ \\
\hline Água Saneamento & 1 & $22 \%$ \\
\hline Energia Elétrica & 8 & $16 \%$ \\
\hline $\begin{array}{l}\text { Total (empresas ISE que } \\
\text { publicam Balanço Social) }\end{array}$ & 17 & \\
\hline \multicolumn{3}{|l|}{ Média setores } \\
\hline \multicolumn{3}{|l|}{ Desvio-padrão } \\
\hline \multicolumn{3}{|l|}{ Média 17 empresas } \\
\hline \multicolumn{3}{|l|}{ Desvio-padrão 17 empresas } \\
\hline Máquinas e Equipamentos & 1 & $0 \%$ \\
\hline Produtos de Uso Pessoal & 1 & $0 \%$ \\
\hline Construção e Engeniaria & 1 & $0 \%$ \\
\hline Saúde & 1 & $0 \%$ \\
\hline Intermediação Financeira & 4 & $0 \%$ \\
\hline Previdência e Seguros & 1 & $0 \%$ \\
\hline Madeira e Papel & 1 & $0 \%$ \\
\hline Químicos & 1 & $0 \%$ \\
\hline Siderurgia e Metalurgia & 1 & $0 \%$ \\
\hline Telefonia Fixa & 1 & $0 \%$ \\
\hline Telefonia Móvel & 1 & $0 \%$ \\
\hline Energia Elétrica & 3 & $0 \%$ \\
\hline $\begin{array}{c}\text { Total (empresas ISE que } \\
\text { não publicam Balanço } \\
\text { Social) }\end{array}$ & 17 & \\
\hline Total ISE & 34 & \\
\hline Média todos os setores & & $29 \%$ \\
\hline Desvio-padrão & & 0,61 \\
\hline Média (34 Empresas) & & $23 \%$ \\
\hline Desvio-padrão & & 0,48 \\
\hline
\end{tabular}


Responsabilidade Social em Relação ao Público Interno: Um Estudo Comparativo entre as

Empresas do ISE e do IBrX

Letícia Tessmann, Angela Patrícia Bovolini Pedron, Mariana Manfroi da Silva, Rubens dos Santos

As empresas dos setores de Alimentos Processados, Telefonia Móvel e Aeroespacial também são as que mais despendem recursos em favor de seus funcionários, com os percentuais respectivos de $252 \%, 116 \%$ e $77 \%$, os demais setores seguem investindo menos de $100 \%$.

Considerando os dados das empresas integrantes do $\mathrm{IBrX}$, os investimentos sociais internos, excetuando-se a folha de pagamento, constam na Tabela 5. 
Responsabilidade Social em Relação ao Público Interno: Um Estudo Comparativo entre as

Empresas do ISE e do IBrX

Letícia Tessmann, Angela Patrícia Bovolini Pedron, Mariana Manfroi da Silva, Rubens dos Santos

Tabela 5 - Outros Investimentos Sociais Internos em Relação ao Resultado Operacional - IBrX

\begin{tabular}{|c|c|c|}
\hline Setor & Qtd. De empresas & Part. FP/RO \\
\hline Comércio e Distribuição & 1 & $128 \%$ \\
\hline Transporte & 3 & $85 \%$ \\
\hline Serviços de Locação & 1 & $49 \%$ \\
\hline Intermediação Financeira & 1 & $31 \%$ \\
\hline Previdência e Seguros & 1 & $82 \%$ \\
\hline Madeira e Papel & 1 & $28 \%$ \\
\hline $\begin{array}{l}\text { Petróleo, Gás e } \\
\text { Biocombustíveis }\end{array}$ & 1 & $22 \%$ \\
\hline $\begin{array}{l}\text { Total (empresas IBRX que } \\
\text { publicam Balanço Social) }\end{array}$ & 10 & \\
\hline \multicolumn{3}{|l|}{ Média setores } \\
\hline \multicolumn{3}{|l|}{ Desvio-padrão } \\
\hline \multicolumn{3}{|l|}{ Média 10 empresas } \\
\hline \multicolumn{3}{|l|}{ Desvio-padrão 10 empresas } \\
\hline Alimentos Processados & 3 & $0 \%$ \\
\hline Bebidas & 1 & $0 \%$ \\
\hline Fumo & 1 & $0 \%$ \\
\hline Diversos & 1 & $0 \%$ \\
\hline Construção e Engeniaria & 4 & $0 \%$ \\
\hline Comércio & 2 & $0 \%$ \\
\hline Exploração de Imóveis & 2 & $0 \%$ \\
\hline Holdings & 2 & $0 \%$ \\
\hline Serviços Financeiros & 3 & $0 \%$ \\
\hline Mineração & 2 & $0 \%$ \\
\hline Siderurgia e Metalurgia & 1 & $0 \%$ \\
\hline $\begin{array}{l}\text { Petróleo, Gás e } \\
\text { Biocombustíveis }\end{array}$ & 1 & $0 \%$ \\
\hline Telefonia Fixa & 1 & $0 \%$ \\
\hline $\begin{array}{c}\text { Total (empresas IBRX que não } \\
\text { publicam Balanço Social) }\end{array}$ & 24 & \\
\hline Total IBRX & 34 & \\
\hline Média todos os setores & & $23 \%$ \\
\hline Desvio-padrão & & 0,37 \\
\hline Média (34 Empresas) & & $19 \%$ \\
\hline Desvio-padrão & & 0,45 \\
\hline
\end{tabular}

setor que apresenta maior volume de benefícios aos seus colaboradores em relação ao montante do resultado operacional é o setor de comércio e distribuição com $128 \%$, seguido do setor de transporte com $85 \%$, e do setor de previdência e seguros com $82 \%$.

Pelos dados obtidos pode-se verificar uma média maior de investimentos no público interno (exceto folha de pagamento) das empresas constantes no ISE; $29 \%$ 
daquelas que apresentam o balanço social e $23 \%$ das que não divulgam o balanço social; em relação às constantes no $\mathrm{IBrX} ; 23 \%$ daquelas que apresentam o balanço social e $19 \%$ das que não o divulgam.

As empresas do ISE mostram-se mais comprometidas em investir em seus funcionários tanto em termos de remuneração pelos serviços prestados, como em relação aos demais benefícios oferecidos aos funcionários. Muitas vezes o acionista opta por investir em empresas que Ihe dão uma maior rentabilidade financeira, em detrimento daquelas que buscam uma postura ética diante da sociedade, entretanto esta visão aos poucos está se modificando, tanto que há empresas do ISE que também estão classificadas entre as empresas do IBrX.

A pesquisa ainda revela que muitas empresas investem bem abaixo do seu resultado operacional no seu maior bem, ou seja, nos colaboradores, um capital muito valioso para o bom andamento dos negócios. No entanto, as empresas do ISE mostram uma boa perspectiva de que o investimento em público interno só tende a crescer.

\section{CONCLUSÃO}

O presente artigo objetivou revelar o quanto as empresas investem em seus funcionários em relação ao seu resultado operacional, sabendo-se que o crescimento do resultado operacional das empresas não se compara ao aumento dos salários e as melhorias referentes aos benefícios oferecidos aos funcionários.

A divulgação de balanços sociais está fortemente ligada ao compromisso que as entidades possuem em relação à sociedade, o que pode ser visto no estudo apresentado observando-se a Tabela 1 , pois as empresas integrantes do ISE publicaram 17 balanços sociais ao passo que as do $\mathrm{IBrX}$ publicaram 10 no ano de 2009. De qualquer forma, observa- se que ainda é baixo o número de empresas que publicam seus balanços sociais.

A análise dos dados apresentados evidencia um maior investimento em folha de pagamento das empresas constantes no ISE em relação às do $\mathrm{IBrX}$. Este fato corrobora com a composição do índice, pois as empresas que compõem o ISE 
reconhecidamente adotam práticas de responsabilidade social.

Algumas análises ficam prejudicadas em função de alguns setores não publicarem balanço social. Um destes setores é o de serviços financeiros, que compõem a amostra com quatro empresas deste setor e apenas uma possui publicação, sendo esta constante do ISE. Contudo, nessa publicação verifica-se um percentual baixo de investimento em folha, informação que precisa ser melhor analisada, pois não se analisa neste estudo a equidade entre os resultados operacionais dentre os vários setores, de tal forma que pode não ser o investimento em folha baixo, mas sim a lucratividade desta empresa ser maior em relação às demais.

Considerando o investimento no público interno que abrange benefícios como gastos com alimentação, contribuições compulsórias, educação, auxílio-creche e participação nos resultados, verifica-se pequena vantagem para as empresas constante no ISE, que em média investem $23 \%$ do seu resultado operacional com o seu público interno ao passo que as empresas constantes no IBrX investem 19\%.

Este estudo serviu também para evidenciar outras formas de análise dos investimentos da empresa com os diferentes públicos. Nesta pesquisa fez-se a comparação entre o percentual da folha de pagamento e seu resultado operacional. As empresas também são instigadas a buscarem outros meios de demonstração dos valores que são investidos nos diferentes públicos, proporcionando aos acionistas elementos mais completos para comparação do que está sendo investido em relação a sua receita bruta, operacional, entre outras análises, que não só a Demonstração do Valor Adicionado (DVA).

Para futuros estudos, indica-se a comparação entre os diferentes públicos: interno, externo e meio ambiente, procurando identificar em qual destes públicos as empresas estão mais investindo.

\section{REFERÊNCIAS}

ASHLEY, Patrícia A. Ética e responsabilidade social nos negócios. 1. ed. São Paulo: Saraiva, 2002.

ARRUDA, Maria Cecília Coutinho de; WHITAKER, Maria do Carmo; RAMOS, José 
Maria Rodriguez.

Fundamentos de ética empresarial e econômica- 3. ed. São Paulo: Atlas, 2005. BATISTA, Halcima Melo. Balanço Social: Uma Mudança de Estratégia a Favor da Política Social. In: XVI Congresso Brasileiro de Contabilidade. Anais... Goiânia, 2000.

BULLARA, César F. C. As Exigências de uma Política de Responsabilidade Social. In: VI Congresso Latino-Americano de Ética, Negócios e Economia. Anais... São Paulo, 2003, p. 1-7.

COMISSÃO DAS COMUNIDADES EUROPÉIAS. Livro verde: Promover um quadro europeu para a responsabilidade social das empresas. Bruxelas, 2001.

ENDERLE, George. Competência global e responsabilidade corporativa das pequenas e médias empresas. In: Construir confiança: ética da empresa na sociedade da informação e das comunicações. São Paulo: Loyola, 2007.

GARCÍA-MARZÁ, Domingos. Ética empresarial: Del diálogo a la confianza. Madrid: Editorial Trotta, 2004.

GIL, Antônio Carlos. Métodos e técnicas de pesquisa social. 5. ed. São Paulo: Altas, 1999.

LISBOA Lázaro Plácido; RIBEIRO, Maisa de Souza. Balanço Social. Revista Brasileira de Contabilidade. Brasília - DF: ano 28, no 115, p.72-81, jan/fev.1999.

LOURENÇO, A. G. ; SCHRÖDER, D. S. Vale investir em Responsabilidade social Empresarial? Stakeholders, ganhos e perdas. In: Responsabilidade Social nas Empresas: a contribuição das universidades, v. II. SP: Peirópolis: Ethos, 2003.

MEIRA, Paulo Ricardo; OLIVEIRA, Renato Luiz Tavares. Ética e marketing e o novo consumidor brasileiro: teoria e prática para o administrador responsável. Porto Alegre: Editora UniRitter, 2006.

MILANI FILHO, Marco Antonio Figueiredo. Responsabilidade Social e Investimento Social Privado: entre o discurso e a evidenciação. Revista Contabilidade e Finanças. São Paulo, v.19, no 47, mai/ ago 2009, p.89-101.

PIZZI, Jovino. Ética e Éticas aplicadas: a reconfiguração do âmbito moral. Porto Alegre: EDIPUCRS, 2006.

SILVA, Antonio Carlos Ribeiro da. Metodologia da pesquisa aplicada à contabilidade: orientações de estudos, projetos, artigos, relatórios, monografias, dissertações, teses. 2 ed. São Paulo: Atlas, 2006. 
Responsabilidade Social em Relação ao Público Interno: Um Estudo Comparativo entre as

Empresas do ISE e do IBrX

Letícia Tessmann, Angela Patrícia Bovolini Pedron, Mariana Manfroi da Silva, Rubens dos Santos

Data de Submissão: 08/11/2010

Data de Aceite: 27/08/2011 